\title{
EDITORIAL
}

\section{Oil spills: microorganisms to the rescue?}

\author{
The oil spill in the Gulf of Mexico is a disaster that will affect wildlife in the oceans and on the \\ shores for a long time. But can microorganisms come to the rescue?
}

Every year, 1,300,000 tonnes of oil enter the environment, for the most part through natural petroleum seeps. The fact that beaches are not perpetually covered with tar balls is due to the activity of microorganisms that can degrade the released petroleum. These include species of the genera Alcanivorax, Cycloclasticus and Thalassolituus, which can degrade various branched-chain and straight-chain saturated hydrocarbons and even polycyclic aromatic hydrocarbons; in fact, for some species hydrocarbons are the sole carbon source ${ }^{1}$. Oil release from petroleum seeps is slow, allowing the local microbial communities to degrade the oil as it enters their environment. Thus, bacteria constitute a natural mechanism for cleaning up oil in the environment. However, during manmade oil spills, such as the current spill in the Gulf of Mexico, the amount of oil can overwhelm the natural microbial community, allowing the oil to spread and wash up onshore, leading to substantial environmental and ecological problems.

Can the natural ability of microorganisms to degrade oil be harnessed to clean up oil spills? In the open ocean, there is often not much that can be done, owing to the sheer size of the affected area. However, there are two approaches that can be used when oil washes onshore: introduction of bacteria that degrade oil (known as seeding) and fertilization to increase the growth of the natural microbial flora. Seeding, with either natural isolates or, potentially, new and engineered bacteria, has shown promise in laboratory tests, but field trials have shown mixed results at best, and in several cases no benefit was observed. Oil spills lead to rapid changes in the composition of the natural bacterial flora; oil-degrading bacteria that are nearly undetectable before release of the oil can become dominant in its presence. Thus, the introduced bacteria are likely to add little to the natural flora. Indeed, in the Gulf of Mexico the reduced oxygen levels around the oil in open water indicate bacterial proliferation in response to the presence of oil. Although these changes seem to be slow from our human perspective, ecologically they are rapid changes that show that the natural response is efficient, especially in open waters.
However, fertilization of the natural flora has proved more successful, although the increased rate of oil removal seen with this approach is still measured in days, weeks and even months; bacteria do not provide a 'quick fix' that rapidly scrubs the beaches clean. In an oil-rich environment, the limiting nutrients for bacterial growth are nitrogen and, to a lesser extent, phosphorus. Fertilizers containing nitrogen and phosphorus therefore stimulate bacterial growth and increase the rate of oil removal. One of the first trials of this approach, in 1976, showed that addition of fertilizers can increase the rate but not the extent of oil degradation. Trials in Prince William Sound in Alaska, USA, after the Exxon Valdez spill have shown that this method is effective in practice.

It is perhaps disappointing that microbiological approaches for oil removal have not improved much since the clean up of the Exxon Valdez spill in 1989, despite our vastly greater understanding of the microbiology of oil degradation and of the manipulation of bacterial metabolic pathways. This may reflect the difficulty in improving an already rather efficient system but, as Jan van der Meer, one of the coordinators of the Bacterial Abiotic Cellular Stress and Survival Improvement Network (BACSIN) states, "we are obviously a bit frustrated that we do not have 5,000 tons or so of specifically formulated active Alcanivorax borkumensis in stock to bring out in the Gulf of Mexico".

It is encouraging that the US National Science Foundation has announced the availability of rapidresponse grants to look at the natural response to the oil spill and has already awarded grants to study the short-term and long-term effects of the spill on microorganisms. More in-depth knowledge of the microbial response will undoubtedly allow more applications of microbial oil degradation for clean-up during future spills. But this requires that funding agencies become and remain committed to funding for research into bioremediation as well as oil breakdown and its applications.

Head, I. M., Jones, D. M. \& Röling, W. F. M. Marine microorganisms make a meal of oil. Nature Rev. Microbiol. 4, 173-182 (2006). 